\title{
Compliant to Warfarin Therapy after Mechanical Heart Valve Replacement
}

\author{
Ragab S. Shehata1, Ahmed A. Elassal'2, Ayman A. Gabal' \\ ${ }^{1}$ Registrar Cardiothoracic Surgery, King Abdul-Aziz University Hospital, Jeddah, KSA \\ ${ }^{2}$ Lecturer Cardiothoracic Surgery, Zagazig University, Zagazig, Egypt \\ Email: ayman67gabal68@gmail.com, openheart32@yahoo.com, elassalcts2000@yahoo.com
}

Received 1 March 2014; revised 1 April 2014; accepted 8 April 2014

Copyright (C) 2014 by authors and Scientific Research Publishing Inc.

This work is licensed under the Creative Commons Attribution International License (CC BY). http://creativecommons.org/licenses/by/4.0/

(c) (i) Open Access

\begin{abstract}
Introduction: Effective anticoagulation depends on demographic factors, patient education, drug knowledge and compliance. The aim of our study is to determine the factors that influence compliance to warfarin in the mechanical valve patient population and its relationship with thrombo-embolic and bleeding events. Patients and Methods: 113 patients underwent mechanical valve replacement (Aortic, mitral or both) at King Abdul-Aziz University Hospital, from 2006 to 2012, patients divided into two groups according to warfarin compliant. Results: 113 patients reviewed in our study, $69(61.1 \%)$ patients found compliant, $36(31.9 \%)$ patients found non compliant, and $8(7.1 \%)$ patients missed. The mean age for all patients was $39.25 \mathrm{y}: 76$ (67.3\%) ware male, 37 (32.7\%) were female. Mean age for compliant patients was 40.19 y versus $33.3 \mathrm{y}$ for noncompliant patients with $p$ value 0.017 . Male patient less complaint than female with significant 0.01 , the mean frequency of follow up was less (32.32 days) in compliant vs. (67.73 days) in non complaint patient. Conclusion: younger age, female gender, Arabic race, assistance at home, education, and single drug use are factors associated with patient compliant, non compliance are associated with higher mortality and valve related complication.
\end{abstract}

\section{Keywords}

Warfarin, Compliant, Mechanical Valve, Replacement

\section{Introduction}

Patients who have undergone mechanical valve implantation require lifelong oral anticoagulation treatment to allow adequate valve function and prevent thromboembolism [1]. These patients require regular clinic visits in order to monitor their International Normalized Ratio (INR), which reflects the level of anticoagulation. Warfa- 
rin, however, is a far-cry from a perfect drug due to its narrow therapeutic index, increased risk of life-threatening bleeding and its multitude of food and drug interactions [2].

Effective anticoagulation is also dependent on addressing a number of patient-related factors. These include demographic factors, patient education, drug knowledge and compliance [3] [4]. Drug compliance has been shown to play a role in inconsistent INR levels. Poor compliance has been found to be responsible for $28 \%$ of INR levels above 6 [5]. Another study showed that 36\% of out-of-range INR readings were secondary to noncompliance [6].

Certain demographic and social factors can play a role in adherence to anticoagulation in different diseases. These tend to be younger patients, patients with non-ischemic etiology, and patients did not know why they are taking anticoagulation [7] [8]. The aim of our study is to determine the factors that influence compliance to warfarin in the mechanical valve patient population and its relationship with thrombo-embolic and bleeding events.

\section{Patients and Methods}

One hundred thirteen patients underwent mechanical valve replacement (Aortic, mitral or both) at King AbdulAziz University Hospital, Jeddah, KSA, Cardiac Surgery department from 2006 to 2012. All patient data was retrospectively collected and reviewed through our data system and telephone contact with patients. Only patients with isolated mechanical valve replacement were included in this study. Patients who underwent bioprosthetic valves were excluded from our study. Patient considers compliant if he regularly following not maximum to 6 week, and taking the correct dose at correct interval.

Data Collection and Statistical Analysis

Data collected through patient interview during clinic visits and through INR test interval monitoring and levels. Patient interview included questions about prior use of warfarin, number of medications, employment status, graduation level, marital status, transportation method, bleeding and Thromboembolism events.

\section{Results}

One hundred thirteen patients reviewed in our study, sixty nine (61.1\%) patients found compliant, thirty six (31.9\%) patients found non compliant, and eight (7.1\%) patients missed. The mean age for all patients was 39.3 years, seventy six (67.3\%) ware male, thirty seven (32.7\%) were female, the duration of follow up range from 3 to 81 months with mean of 56.8 months, aortic valve used in thirty three (29.2\%) patients, mitral valve used in fifty three (46.9\%) patients, both valve are used in twenty seven (23.9\%) patients, Table 1.

Compliant patients were older age, mean age 40.19 years versus 33.3 years for noncompliant patients with $p$ value 0.017 . Male patients less complaint than female with significant $P$ value 0.01 , Arabic race is more complaint than African and Asian races with significance p value 0.003, the mean frequency of follow up was less 32.32 days in compliant vs. 67.73 days in non complaint patient, the mean warfarin dose was $3.29 \mathrm{mg}$ in compliant, vs. $4.05 \mathrm{mg}$ in non compliant patients. No significant effect of marital status or employment status on complaint with $\mathrm{p}$ value 0.14 ., 0.83 respectively, there are significant effect of home assistance, single drug use, education level on complaint with P value $0.049,0.024,0.037$ respectively, Table 2.

During follow up period there are two (3\%) deaths in compliant group, all due to unrelated valve problems, in non compliant group there are two (5.7\%) deaths due to valve related complications, three (8.3\%) deaths due to other valve problems. Two (3\%) patients had bleeding complication (epistaxis, haematemsis), one (1.5\%) patient had valvular thrombosis in complaint group. In non complaint group there are seven (19.4\%) patients had bleeding complications, and three (8.3\%) patients had thrombo-embolic valve event, Table 3.

\section{Discussion}

Previous studies showed that patient compliance is crucial in adequate anticoagulation therapy [3] [4]. The cohort study of Waterman et al. showed that $23 \%$ of all international normalized ratio (INR) values for the anticoagulant warfarin were outside the target range. Thirty-six percent of these values could be explained by changes in the patient's eating behavior, misunderstanding of the drug dose, skipping a dose, missing consultations in an outpatient clinic, excessive consumption of alcohol, or failure to obtain timely and correct prescriptions [4].

In our study we found that female gender are more compliant than males, this may be due to that females tend to be careful than males, also older patient tend to be compliant than younger, this goes with results of Arnsten 
Table 1. Demographic data for all patients.

\begin{tabular}{cc}
\hline & $\mathrm{n}(113)$ \\
\hline Age & $(9-66) 39.3 \pm 14.62$ \\
\hline Gender & $76(67.3 \%)$ \\
Male & $37(32.7 \%)$ \\
Female & $72(63.7 \%)$ \\
Race & $13(11.5 \%)$ \\
Arabic & $28(24.8 \%)$ \\
African & \\
Asian & $69(61.1 \%)$ \\
Compliant & $36(31.9 \%)$ \\
Compliant & $8(7.1 \%)$ \\
Non compliant & $(3-81) 56.8 \pm 19.31$ \\
Missed & \\
of therapy/month & $33(29.2 \%)$ \\
Valve Location & $53(46.9 \%)$ \\
Aortic & $27(23.9 \%)$ \\
Mitral & \\
Both & $53(46.9 \%)$ \\
Valve model & $60(53.1 \%)$ \\
St. Jude & \\
ATS &
\end{tabular}

Table 2. Factors affecting compliant.

\begin{tabular}{|c|c|c|c|}
\hline & $\begin{array}{l}\text { Compliant } \\
(\mathrm{n}=69)\end{array}$ & $\begin{array}{l}\text { Noncompliant } \\
\quad(\mathrm{n}=36)\end{array}$ & $\mathrm{p}$-value \\
\hline Age & $40.19 \pm 13.8$ & $33.36 \pm 13.71$ & 0.017 \\
\hline \multicolumn{4}{|l|}{ Gender } \\
\hline Male & $41(59.4 \%)$ & 30 (83.3\%) & \multirow{2}{*}{0.01} \\
\hline Female & $28(40.6 \%)$ & $6(16.7 \%)$ & \\
\hline \multicolumn{4}{|l|}{ Race } \\
\hline Arabic & $52(75.4 \%)$ & 14 (38.9\%) & \multirow{3}{*}{0.003} \\
\hline African & $3(4.4 \%)$ & $9(25 \%)$ & \\
\hline Asian & $14(20.2 \%)$ & $13(36.1 \%)$ & \\
\hline Frequency of follow-up/days & $(23-42) 32.32 \pm 4.21$ & (17 - 273) $67.73 \pm 38.61$ & $<0.001$ \\
\hline Warfarin dose & $3.29 \pm 1.45$ & $4.05 \pm 1.19$ & 0.008 \\
\hline Mean INR & $2.28 \pm 0.61$ & $2.18 \pm 0.65$ & 0.43 \\
\hline \multicolumn{4}{|l|}{ Marital status } \\
\hline Single & 12 & 11 & \multirow{2}{*}{0.14} \\
\hline Married & 57 & 25 & \\
\hline \multicolumn{4}{|l|}{ Assistance at home } \\
\hline Yes & 51 & 19 & \multirow[b]{2}{*}{0.049} \\
\hline No & 18 & 17 & \\
\hline \multicolumn{4}{|l|}{ Employment } \\
\hline Employed & 41 & 20 & \multirow{2}{*}{0.83} \\
\hline Unemployed & 18 & 16 & \\
\hline \multicolumn{4}{|l|}{ Number of drugs } \\
\hline Single & 45 & 21 & \multirow{2}{*}{0.024} \\
\hline Multiple & 24 & 36 & \\
\hline \multicolumn{4}{|l|}{ Education Level } \\
\hline Educated & 46 & 16 & \\
\hline Uneducated & 32 & 20 & 0.037 \\
\hline
\end{tabular}


Table 3. Mortality and complications.

\begin{tabular}{cccc}
\hline Complications & Compliant $(\mathrm{n}=69)$ & Non-compliant $(\mathrm{n}=36)$ & $\mathrm{p}$-value \\
\hline Status: & & & \\
Living & $67(97 \%)$ & $31(86 \%)$ & 0.051 \\
Death due to valve & $0(0 \%)$ & $2(5.7 \%)$ & \\
Death due to other & $2(3 \%)$ & $3(8.3 \%)$ & \\
Complications & & & \\
Bleeding & $2(3 \%)$ & $7(19.4 \%)$ & 0.003 \\
Thrombo-Embolism & $1(1.5 \%)$ & $3(8.3 \%)$ & \\
\hline
\end{tabular}

and colleague, they noticed that male gender and younger age patient were frequently not compliant to warfarin, [8], also we observed that Arabic race were compliant than others, this may due to better understanding of Arabic languish and languish barrier in others. Non compliant group take higher dose of warfarin to achieve target INR than compliant group. Married patients tend to be more compliant than single, but without significant difference, because those married patients may have some assistant at home, but in real assistance at home from other family members those patients had significantly higher compliance.

In our study, we observed two of most important factors in patient compliant; single drug use and education level, patient only take warfarin was higher complaint to dose adjusting and follow up, also patient educated in more compliant to warfarin than non educated patient with significantly statistical difference. This result in the same line with Platt A. and collegues, they concluded that: Poor adherence to warfarin is common and risk factors are related to education level, employment status [9]. We observed higher mortality and valve related complication in non compliant group, also bleeding complications in higher in those groups with significant difference, most of reviewed studies showed unstable INR is major factor in valve thrombosis and bleeding complication [10].

\section{Conclusion}

We concluded that younger age, female gender, Arabic race, assistance at home, education, and single drug use are factors associated with patient compliant. Non compliance is associated with higher mortality and valve related complication.

\section{References}

[1] Kulik, A., et al. (2006) Early Postoperative Anticoagulation after Mechanical Valve Replacement: A Canadian Survey. Journal of Heart Valve Disease, 15, 581.

[2] Hirsh, J., et al. (2001) Oral Anticoagulants: Mechanism of Action, Clinical Effectiveness, and Optimal Therapeutic Range. CHEST Journal, 119, 8S-21S. http://dx.doi.org/10.1378/chest.119.1 suppl.8S

[3] Tang, E.O., Lai, C., Lee, K., Wong, R., Cheng, G. and Chan, T. (2003) Relationship between Patients’ Warfarin Knowledge and Anticoagulation Control. Annals of Pharmacotherapy, 37, 34-39.

[4] Roddie, A.M.S. and Pollock, A. (1988) Therapeutic Control of Anticoagulation: How Important Is Patient Education? Clinical \& Laboratory Haematology, 10, 109-112.

[5] Brigden, M.L., Kay, C., Le, A., Graydin, C. and McLeod, B. (1998) Audit of the Frequency and Clinical Response to Excessive Oral Anticoagulation in an Outpatient Population. American Journal of Hematology, 59, 22-27. http://dx.doi.org/10.1002/(SICI)1096-8652(199809)59:1<22::AID-AJH5>3.0.CO;2-1

[6] Waterman, A.D., Milligan, P.E., Bayer, L., Banet, G.A., Gatchel, S.K. and Gage, B.F. (2004) Effect of Warfarin Nonadherence on Control of the International Normalized Ratio. American Journal of Health-System Pharmacy, 61, 12581264.

[7] Pamboukian, S.V., Nisar, I., Patel, S., Gu, L., McLeod, M., Costanzo, M.R. and Heroux, A. (2008) Factors Associated with Non-Adherence to Therapy with Warfarin in a Population of Chronic Heart Failure Patients. Clinical Cardiology, 31, 30-34.

[8] Arnsten, J.H., Gelfand, J.M. and Singer, D.E. (1997) Determinants of Compliance with Anticoagulation: A Case-Control Study. American Journal of Medicine, 103, 11-17. http://dx.doi.org/10.1016/S0002-9343(97)90048-6

[9] Alec, B., Platt, M.D., Russell Localio, A., Colleen, M., Brensinger, M.S., Dean, G.C., Jason, D.C., Robert Gross, M.D., 
Catherine, S.P., Maureen Price, R.N., Joshua, P.M., Abigail, C., Craig, W.N., Brian, L.S., Mitchell, S.L. and Stephen, E.K. (2008) Risk Factors for Nonadherence to Warfarin: Results from the IN-RANGE Study. Pharmacoepidemiology and Drug Safety, 17, 853-860.

[10] Bourguignon, T., Bergöend, E., Mirza, A., Ayegnon, G., Neville, P., Aupart, M.R. and Marchand, M. (2011) Risk Factors for Valve-Related Complications after Mechanical Heart Valve Replacement in 505 Patients with Long-Term Follow-Up. The Journal of Heart Valve Disease, 20, 673-680. 